\title{
Activity Based Teaching of Concept Types
}

\author{
Dilek Başerer ${ }^{1, *}$ \\ ${ }^{1}$ Turkish and Social Sciences Education Department, Philosophy Group Education Department, Kazım Karabekir \\ Education Faculty, Erzurum, Turkey \\ *Correspondence: Turkish and Social Sciences Education Department, Philosophy Group Education Department, \\ Kazım Karabekir Education Faculty, Erzurum, Turkey. E-mail: dilek.baserer@atauni.edu.tr
}

Received: August 12, 2020

doi:10.5430/wje.v10n5p122

Accepted: September 3, $2020 \quad$ Online Published: October 10, 2020

URL: https://doi.org/10.5430/wje.v10n5p122

\begin{abstract}
Learning with activities is a method of learning where learning process is much easier with practical applications rather than theoretical structure of information given to learn a subject. As learning with activities contain practical applications, it is of great importance in teaching a learning outcome of any teaching program. For that reason, it is likely to teach the outcomes in the program of logic teaching by means of learning with activities. The current study was carried out for this reason. In the study, how the learning outcome of "Classification of the Types of Concept" could be taught with activities in the unit of classical logic in the logic course of the latest 2009 program was elaborated. In this way, it was tried to form an easy learning module by given examples regarding such kind of activities of the outcomes in teaching logic. The study is of importance in terms of obtaining a learning outcome by means of teaching with activities.
\end{abstract}

Keywords: teaching program, 2009 teaching program of logic, types of concept, activity based teaching

\section{Introduction}

Activity-based learning is a type of learning used in education and training process and based on various activities. This style of learning helps students to understand the subject more actively. This learning, which is used especially in learning outcomes, forms the basis of permanent learning. In this way, the information desired to be taught is taught more easily. Activity-based learning, which can be applied to the acquisitions in each curriculum, can also be used for teaching concept types. In the research created for this purpose, the activity-based teaching of "classifies the types of concepts" in the 2009 logic curriculum was examined. The study is important to show how the activity-based teaching of the subject in the logic course can be. Therefore, "How should activity-based teaching for the learning outcome of 'perceives the types of concept' taking place in the teaching program of logic be?" The question constitutes the main problem of the study. Sample activities related to the acquisition in the study are included. It is thought that these activities set an example for effective learning with other gains.

\subsection{Teaching Program}

A program is to determine in advance and reveal the possible answers to such questions of "Why?, In which ways?, How?, How long?, In which settings?, How much? etc." benefitting from the current knowledge for the sake of reaching a certain purpose (Demirel, 2009; Sönmez, 2001).

"Teaching program is the systematic grouping of the courses or the formation of the courses needed to be graduated from a certain basic major" (Olivia, 1988: 6). According to Ornstein \& Hunkins (1986:6), teaching program is "a plan or a written text having necessary strategies in order that we can reach the desired objectives regarding an activity".

Teaching program is a whole comprising such components as teacher, subjects, physical facilities, course materials etc. that are necessary for the objectives to be attained in the educational program (Calp, 2006). Each component in this unity should be complete and sufficient in order that the program could be successful. At the application stage of the teaching program, any insufficiency and problem occurring in these components would lead to lack of understanding of the course by the students. Teaching programs in the educational program comprise the part of education regarding the courses. The teaching program within the educational program is the most important 
component (Küçükahmet, 2007).

Defined as all the activities carried out both in and out of school, educational program is a systematic process offering individuals learning experiences (Demirel, 2009). As for the definitions with regard to educational program, it is likely to see that it mostly deals with planning and the activities made, in other words, with the concept of learning experiences. Comprising all of the planned educational status aiming at training students in a certain time, educational programs have four major components. These are objectives (learning outcomes), content, learning experiences (educational status) and evaluation activities (Calp, 2010).

The standard of the behavioural changes which educational institutions aim upon students are defined by objectives (learning outcomes). "Determining objectives in planning process, determining target fields, determining prerequisite learnings, determining student qualities, arranging the content, selecting learning strategies and materials, determining teaching activities, determining assessment and evaluation process, application and evaluation of teaching are the major fields that are necessary to be determined" (Senemoğlu, 2004, p. 398-428). "The stage of determining objectives is the part firstly highlighted among the steps determined comes first. What is meant with "objective" in the program is the point to be reached" (Sönmez, 2001, p. 23). "Objective is the desired characteristics which we want an individual should have with a quality of being attained" (Bilen, 2006, p. 9). Objectives express the behaviours that a person to be trained should attain. The question of "Why" is tried to be answered in the dimension of objectives in programs (Demirel, 2009).

\subsection{The Program of Teaching Logic}

Defined as the knowledge of thinking or speaking, as a science of reasoning, proving the result, knowledge of assaying the evidence or science of proving, logic could be expressed as a tool allowing to find what is true in the end by using the rules and ways of true thinking in an effective and conscious way and by reasoning (Y1ldirım, 1976; Emiroğlu, 2004; Duman, Arslan \& Küçükşabanoğlu, 2018). Given that every course has a teaching program, the teaching program of logic shows in which topics and framework the course of logic will be taught. Currently, 2009 teaching program for the course of logic is being taught. For that reason, the objectives and purposes of the teaching program of logic are given as in 2009 teaching program of logic.

The objective of the Teaching Program for the Course of Logic is; to train individuals who can think independently, transfer true thinking ways to daily life, be aware of contradicts, think consistently, base his thoughts and offer solutions for the problems encountered (Teaching Program for the Course of Logic, 2009).

General objectives of the Teaching Program for the Course of Logic are; that students completing the course of logic can reach the information that logic is related to reasoning which is a type of thinking, they can develop the features of being systematic and careful, they can base the correctness of knowledge, they can transfer the ways of thinking correctly into daily life, they can be aware of their own thinking ways, they can develop awareness against contradictory thoughts, they can supervise the consistency of thoughts, they attain the skill of being consistent while thinking, they use language correctly and neatly while conveying their thoughts and that they can express daily language by means of the language of logic (Teaching Program for the Course of Logic, 2009).

Teaching Program for the Course of Logic was prepared as two course hours and seventy-two hours in total in an academic year. (Teaching Program for the Course of Logic, 2009). Regarding teaching of this course (Teaching Program for the Course of Logic, 2009):

The learning outcomes regarding the units were determined in a way to reach the general objectives of the course of logic. Teaching periods and the levels of students were taken into consideration in the duration of unites and the order of teaching the units. Paying attention to the student levels and environmental factors, the interrelated learning outcomes in the units different from learning and teaching activities were given together. Learning, teaching methods and techniques making students active depending on the student level, educational environment and environmental factors were used in learning - teaching activities. The approach of teaching subjects to students by making them enjoyed was adopted. The program table where there are learning outcomes, sample activities and explanations is of great importance. While making a preliminary preparation for the course of logic, general objectives of the course, unit outcomes and explanations were taken into consideration. The activities in the program are exemplary. The teacher could develop similar activities in line with the interests, needs and differences of the students by benefitting from sample activities. Teaching of the course and the activities should be aiming at making the students attain and develop the skills of being able to convey the ways of thinking correctly to daily life, being able to think consistently and be aware of differences. In the evaluation of students, it is likely to benefit from the sample evaluation forms given in the program. These forms could be used as they are and also the teacher could develop new forms. The 
objectives and learning outcomes comprise knowledge, skills, attitudes and habits that students would attain in teaching process. The teaching program of the course of logic is made up of 4 units and 53 learning outcomes. One of these outcomes is "Classifying the types of concepts" in the unit of classical logic.

\subsection{Types of Concepts}

Concept is the correspondence of a phenomenon or an object in thought while term is the expression of this correspondence by tongue (Çüçen, 2013). No thought is realized without a concept and it is not possible to express thoughts without terms.

Concepts bear the characteristics of the beings they represent. In this sense, they have types. The concepts expressing an object or a being are defined as concrete and those expressing the style of occurrence are defined as abstract (Öner, 2014). "Positive concepts are the ones expressing that there is a quality in the thing pointed while negative concepts are the ones expressing that there is no quality in the thing pointed. Such concepts as 'virtuous', 'rusty', 'dirty', 'honourable' etc. are positive concepts and concepts like 'unvirtuous', 'dishonest', 'unskilful' etc are negative concepts (Özlem, 2004, p. 80). If something designed in mind corresponds to a single being, this concept is singular, if it corresponds neither a single nor all beings but only one part, it is a particular concept and if it corresponds to the common features of the beings in the same kind or to all, it is called a general concept. Besides that, "when individuals express a group and the concepts are realized in the group, they are called collective concept, such as the concepts of army, union, family, assembly. The concepts that individuals point to a group but it is realized at individual are called distributive concepts just as the concept of soldier has its meaning in the concept of army and the concept of worker has its meaning in the concept of union (Çapak, 2015, p. 89). Another concept is the concept of dependant. In a dependant concept, it is not possible to think of an object pointed by a concept without another object. As an example, in order that the term of mother points to a person, it is necessary that this person must be her son. Another concept is the concept or term of absolute. Absolute concept is called as a term or concept which is able to point to an object without a need for an existence of another concept like water, gas, tree (Ural, 2011).

\subsection{Activity-Based Teaching}

Activity is the events that students are made to carry out with various concrete materials in order to make a concept, a rule understandable easily (Koç et al., 2020). Started by Diane Bricker from the University of Oregon and her colleagues, Activity Based Teaching (ABT) is teaching structure which is in a significant and natural relation with behaviour, where the stimulants are used before and after behaviour, offering learning opportunities to child before he interferes on his own and where the certain objectives are taught by putting into the activities formed before depending on the interests of child (Pretti-Frontczak, Barr, Macy \& Carter, 2003, Pretti-Frontczak \& Bricker; 2004; Özen \& Ergenekon, 2011). Activity-based teaching process comprises a style of teaching which is task oriented, learner centred, based on skill and perception, benefitting from the activities where various teaching techniques and methods are used. The purpose here is to attain the skills of analysing, applying and synthesizing and it is not regarded as the fact that students obtain the knowledge and adopt it. Activity-based teaching is a method teaching students how to think with their thinking structure peculiar to them, facilitating to find practical solutions for the problems they experience, making children in the developmental age attain self-confidence in order to facilitate learning (Hee, 2005). Activity - based teaching approach is one of the constructivist learning approaches which student can use in an active learning environment in the process of positive attitude and value attainment (Aktepe, 2010). In training teachers as a preservice education aiming at constructivist learning approach, it is of importance to deal with theoretical and application dimensions. In this way, the activities developed with the components of active learning will lead to a more effective learning by including application dimension as well as theoretical knowledge and student will reach form their own concepts with these activities and reach knowledge directly (Özden, 2009).

\subsection{Purpose of the Study}

Teaching program is a guide or a project showing what should take place, why and how, in the learning and teaching process regarding a course. In a teaching program of a course are the behaviours to be attained by students in the course. While preparing programs, similar behaviours are grouped together and with the same activities (Özçelik, 2009). The learning outcomes in these programs are the objectives to be taught. The current study aims at teaching the outcome of "classification of the types of concepts" taking place in 2009 teaching program of logic more easily and effectively with the activity-based teaching. In this sense, the question of "How should activity-based teaching for the learning outcome of 'perceives the types of concept' taking place in the teaching program of logic be?" was taken as the basic problem in the research. 


\subsection{The Importance of the Study}

Activity - based teaching is a teaching involved by the students actively and the one realized to make the information given more effective and understandable. With this teaching module which is used in order to make the subjects more enjoyable and more understandable, a faster teaching of logic and attainment of the subjects were aimed. Learning the outcomes by means of teaching with activities more comfortably and perceiving the outcomes with the desired way by the student is of importance.

\section{Method}

\subsection{Research Design}

The current study is a descriptive study in the survey model as it reveals the current case, explains the interaction between the cases paying attention to the relation of the current events with former events and conditions and describes a case as it is (Karasar, 1999).

\subsection{Data Collection Tools}

As the data collection tools, various reasoning games (practical glasses, taboo, silent cinema, card matching, tic-tac-boom, hımbil) were used.

\subsection{Data Collection}

Data were collected by benefitting from reasoning games regarding the learning outcome of "classification of the types of concepts" in the unit of classical logic taking place within the content of 2009 teaching program of logic.

\subsection{Data Analysis}

The data obtained through various reasoning games (practical glasses, taboo, silent cinema, card matching, tic-tac-boom, hımbil) were analysed with an adaptation and in relation to the learning outcome. Data were analyzed by adapting mind games to outcome.

\subsection{Validity and Reliability Study}

For the validity and reliability of the study, the cogency showing to what extent findings are consistent with reality for the sake validity and the transmissibility given at what level the findings could be adopted to other contexts. For the reliability of the study, the consistency expressing the variability of which source could be explained was examined. In order to obtain the validity of the study, the consistency of the findings with the data collection tools were controlled and its cogency was tried to be raised. In addition, the research process and what was conducted in this process regarding the cogency of the research was given in detail and validity control was made. In order obtain the reliability of the study, the data was used as it was without making any contribution and the sources extracted were given. In this way, consistency was tried to be increased (Gruba, 1981; Shenton, 2004).

\section{Findings}

Within the scope of the logic course related to activity-based learning, there are only studies conducted by the researcher. Since such studies were not encountered on the subject, the deficiency in the field was tried to be eliminated. Sample activities likely to be done regarding the learning outcome of "classification of the types of concepts" are given below. These sample activities are of the quality of answering the question of "How could these activities be upskilled by the students faster and more effectively?"

\subsection{Activity 1: Practical Glasses}

\subsubsection{Process}

At least two people are needed to play the game. Firstly, the teacher must arrange the desks. Those who are going to play the game must sit closer. It means that there must not be gaps between the desks the students sit. There must be tables in front of the desks the students sit at a level to reach by their arms. The group to play the game must be organized according to the name list of the class. Starting from the first one in the list, the students must be arranged by the teacher depending on the number of the students as the first two, three, four or more in an equal share. All of the ones in the class must involve in the game according to a suitable group list ranking. In this way, the teacher organizes the groups to play the game according to the list. If the group number could not be shared equally, the extra person could be included in the first group, namely the group starting the game in the first place. While making the group list, unattended student that day could be skipped and the arrangement could be made so. The teacher has the task of giving the game cards to the groups that will play the game and he can show the cards as slides in order 
that students can see them more clearly. On the cards or slides are written the vocabulary taught in the course. These are five words in five different colours (yellow, red, green, blue, black) and depending on the writing order, next to or under the words on the cards or slides are figures. These figures are also made up of five colours. They are red, blue, yellow, green and black colours. The word or figure belonging to each colour is only used once. Students can play the game looking at the card or slide. There must be five glasses in different colours in front of each student and these colours are black, green, blue, red and yellow. These glasses must be handed out by the teacher to the group who will play the game. The glasses must on the table where students will play the game in an upside-down position in front of the students. A bell must be placed on the table in the middle in a way each student can reach by using their one hand. Students must add the glasses according to the colours given in the card or slide up or in the way given. The one adding the glasses up in the fastest way or as given in the card must press on the bell. The teacher must assign the student adding the glasses up in the correct way and pressing on the bell one point. Each group must do the figures shown in the card or slide for four or five times and press on the bell. The teacher must decide how many times he will show the card or slide depending on the number of the students and the lesson hour. If the scores of the players in each group are equal, the game can be placed once. Another group must be rearranged with the winners of each group and practical glasses game must be played and the one pressing on the bell the first must be declare the winner. At the end of the lesson, the students will have seen many examples after teaching the subject regarding various concepts and reinforced the lesson.

\subsection{Activity 2. Taboo}

\begin{tabular}{|c|c|c|}
\hline \multicolumn{3}{|c|}{ Sample Cards for Taboo } \\
\hline Distributive Concept & Collective Concept & Particular Concept \\
\hline Soldier & Army & Some Places \\
\hline Civil Servant & Union & Some People \\
\hline Deputy & Assembly & Many People \\
\hline Tree & Forest & Most of People \\
\hline Student & Herd & Commons \\
\hline & \multirow{2}{*}{ Abstract Concept } & Singular Concept \\
\hline Positive Concept & & Eagle \\
\hline Intelligent & Pi Number & Lettuce \\
\hline Skilful & Poetry & Bobcat \\
\hline Powerful & Beauty & Sparrow \\
\hline Moral & Triangle & Orange \\
\hline Strong & Citizenship & \\
\hline \multirow{2}{*}{ Universal Concept } & Negative Concept & Concrete Concept \\
\hline & Reluctant & Pen \\
\hline All Humans & Hopeless & Human \\
\hline All People & Weak & Table \\
\hline Nobody & Unskilful & Poet \\
\hline Each Car & \multirow[t]{2}{*}{ Irrational } & \multirow[t]{2}{*}{ Citizen } \\
\hline All Animals & & \\
\hline
\end{tabular}




\subsubsection{Process}

The types of concepts are taught. After teaching the subject, the teacher tells how the game of taboo is played and what the rules are and then it is played. After the game of taboo finishes, they find which type of concept is the vocabulary desired to be known included.

\subsubsection{How is the Game of Taboo Played?}

The class is divided into two as A and B for the game taboo. The groups, Group A and Group B, sit all together. These groups are noted in a notebook as Group A and Group B. The groups are separated with a line. The reason for this is to take a note for the groups after each giver (the one who describes the word) how many words they guess. The task of taking notes and time is made by the teacher. The game of taboo is time limited and a verbal game and the duration is 60 seconds. The duration is set with a mobile phone chronometer as 60 seconds. After the time is over the buzzer rings and teachers announces that the time is over. In this sixty-second period, the student holds the cards in the form of a rectangular in a way not to see the writing. When time starts, he turns the cards one by one and tries to describe the word without saying 5 forbidden words. A person is chosen from the opposite team to control whether the giver tells the five forbidden words and he follows the cards. If the giver tells one of the forbidden words, the follower warns the giver and if the time is not over, he can go on with other cards. Whoever describes the word has a right to say 'pass' only once (I give this right as the words are difficult to describe). When the time is over, the giver tells how many words he guessed and in which group he is. The teacher takes a note and when the game is over, the scores are calculated and the winner is declared. Each team chooses a person in their team to observe the other team. Each team decides who the giver will be when it is their turn. It the giver group is Group A, as an example, Group B never talks. Only the chosen person from Group B stands by the giver of Group A to control the card. This will be vice versa as well. The rules are the same when they change the roles. It is also forbidden that the giver tells the English meaning of the words. The giver has a right say 'pass', but not a second one. If the time is not over yet, he must go on with the go on with the card in hand without getting another one.

\subsection{Activity 3: Silent Cinema}

\subsubsection{Process}

The teacher tells the types of concepts in accompany with slides to the students in the class. After explaining the subject, he answers the questions, if any. The subject is supported by the game of silent cinema. Before the game starts, the teacher writes the types of concepts side by side in a way to make a classification under them. The teacher tells how the game of silent cinema is paled and what the rules are.

\subsubsection{The Rules of the Game}

The game of silent cinema is played with two teams. Each film is told by a person chosen from the team to his own team. The chosen person tries to tell the film without talking but jut by means of gests and mimics.

The time for each film is 120 seconds. The teacher coordinates the time with a chronometer. If the film is not guessed by the team till the end of the time, the turn passes to the other team. Those not obeying the rules are disqualified. In order not to tell the same film, the paper on which the name of that film is written is separated from the rest.

P.S: The names of the films comprise the types of concepts. The films are determined according to these features.

The teacher divides the class into two equal teams according to the sitting order. In order to determine which team to start the game first, the teacher tosses a coin. A volunteer is chosen from the teach starting the first to tell the film. The volunteer student draws a card from the purse having the film names prepared by the teacher. He tries to tell the films on the paper he choses suitably to his team mates. All the team members try to understand the film. After guessing the film, the giver chooses a person from the opposite team to tell the new film. The newly chosen person draws a card from the purse and tries to tell it to his team mates. The game goes on like this. The teacher collects the papers of the films told during the game. At the end of the game, the team knowing more films wins the game. After the game is over, the teacher and students find together out the concepts and the types of concepts given in the names of the films. They write the types of concepts at a suitable place on the board and classify them.

\subsection{Activity 4: Card Matching}

\subsubsection{Preparation}

The information regarding the subject of the types of concepts is investigated. Two series of cards almost half of the number of students (or at a suitable number for the content) in the class. There are 1definitions and questions 
regarding the subject in one series and the answers of these definitions and question in the other (28 in total in green and red colours). The back side of the red cards are enumerated.

\subsubsection{Process}

Firstly, the subject is presented to the class. After the presentation, the cards are handed out to the class. It is made as single, double etc. depending on the number of the students in the class. The students are given a certain time (3-5 minutes) to allow them to prepare with the cards given. After the time is over, the students walk around the class and try to match the cards by talking to other students. As an example; if it is written "It corresponds just one thing designed in mind" on the card, the card on which "singular concept" is written is tried to be found. Those coming together and matching the cards prepare the reasons for these matches. When the whole class does this process, the number of the cards are announced and the students having the cards present the content and the reasons they prepared to the class.

\subsection{Activity 5: Tic Tac Boom}

\subsubsection{Process}

Firstly, the class is divided into groups (with 6-8 students). The group members are chosen randomly. The group to play the game is asked to make a circular shape. In the centre of the circle, 10 cards prepared regarding the subject taught are placed upside down in a way everybody can see. (If the game will be played with younger groups, the titles could be given with related pictures to give an idea). There is just one bomb in the game. There is an electronic clock to be used in the game with a changeable time. When it is activated, nobody knows the finishing time. The youngest member of the group is given the bomb and the game starts. The bomb is activated by the player pressing on the red button under it. At that time, the player takes the card at the top of the pack and opens it. He puts it at end of the pack. They player having the bomb in his hand looks at the card and tells a word regarding the title in the card. As an example: If the subject in the card is "Collective Concepts", the players must say such words which are a collective concept as assembly, army, public etc. If the word told is correct, he gives the bomb to the student on his left. In order to take the open card, the bomb must explode in the hand of that person. The game restarts with the player in whose hand the bomb explodes. The player opens the card at the top of the pack and he starts the bomb again. The word given by the player could be objected by other players. If a word which is not related to the title of subject in the card is given or a word which is given before is told for the same card, there could be an objection. In this case, the student whose offer is not accepted must tell a new word before delivering the bomb. As soon as the players tell the word, they pass the bomb to the next player quickly and the game goes on. If the bomb explodes at the time of passing and the last told word is correct, it means that it explodes in the hand of the receiver. When all of the 10 cards given at the beginning of the game are played, the game ends. The winner is the one having no card or the least card at the end of the game. In the case of an equality, a second round is made between the players.

\subsubsection{Extra Version of the Game}

The game rules are the same in this version. There are only 1-2 or 3 letters under the title of the related subject written in the cards and under the letter there are words written in red, blue and green colours (in the beginning, in the middle and at the end).

Before starting the game, a common colour must be chosen by the players. What is written in the card (in the beginning, in the middle and at the end) some words must be told regarding it. In other words, depending on each subject written in each card, the students must el words starting, ending or containing word/words written under them and pass the bomb to the next player before it explodes.

P.S: If the instruction required in the card is different, the player whose word is not accepted must tell a new word before passing the bomb.

P.S: If the group to play the game is made up of younger ones (preschool and primary level), in order to facilitate the game, just the word written under the title is taken into consideration. And the subject and words starting with that letter must be told.

\subsection{Activity 6: Humbil}

\subsubsection{Process}

The subject is told. Following that, the students are divided into groups with four depending on their sitting positions starting from the one sitting next to the window in order to make a preliminary work about the game "Himbil". The teacher prepares different colours of paper for each group. He writes sample concepts regarding the types of concepts (universal, particular, general, singular, positive, negative, concrete, abstract, collective, distributive). Depending on 
the number of the players, four sheets of paper are handed out for each player. There are four different sample concepts in each group. These are folded, mixed and dropped on the floor. Each student collects four folded papers. On condition that one never shows another, they unfold the papers. Everybody opens the papers without showing and then one gives one of the papers clockwise to the next player. The players in the group decide who to start. It is carried on until one of them collects the same four concepts (e.g. democracy) by delivering the papers one by one. The one collecting four words the first puts his hand on the place where they play the game (e.g. on the desk if it is a class) and says "Hımbil". Other players put their hands on the hand of the player saying "Himbil". The winner in other words the one making "Himbil" gets the highest score. The first student putting his hand on the winner gets 10 points lower than the winner, the second one gets 20 points lower and the third one gets 30 points lower. (The winner gets 40 points, the second gets 30 points, the third gets 20 points and the fourth gets 10 points). The scores obtained are noted for the players. The game starts again and the scores are noted after each game. After the repetition of the game many times, the scores are added and the winners in each group are determined and they are congratulated. During the game, the teacher writes the types of concepts on the board. After the game finishes, the teacher asks students which type of concepts the concepts used in the game belonged to. The teacher writes the concepts answered by the students in their places on the board. In this way, the classification is completed and the teacher makes an evaluation about whether the concepts are perceived or not.

Table 1. The Concepts Used in the Game "Himbil"

\begin{tabular}{lcccc}
\hline Concrete & Abstract & \multicolumn{1}{c}{ Universal } & \multicolumn{1}{c}{ Particular } & General \\
\hline Car & Democracy & Every country & Some women & Planet \\
Silk worm & Sadness & & & Plants \\
Child & & & \\
Singular & Collective & Distributive & Positive & Negative \\
France & Delegation & Turkish Soldier & Well-Behaved Child & Dead \\
Turkey & Family & General & Hardworking Bees & \\
Teo Grünberg & & Child & & \\
Galatasaray & & & & \\
\hline
\end{tabular}

\section{Discussion and Conclusion}

Teaching programs is a regulatory system for teaching as a product of educational programs. These programs show how and in which order the information given to the students should be. There are various objectives and learning outcomes in a teaching program. The outcomes are the desired features determined to be observed at a person. It is aimed to make to teach the subject and make the students attain by means of these features. In the current study, activity-based teaching was benefitted in order to attain these features. Activity-based teaching was used in order that it would lead to a more effective and active way while conveying the outcome of "Classification of the types of concepts" in 2009 Teaching Program of Logic. For this outcome, it was planned to design various activities samples in order to increase effective learning process of learning. In this way, it was aimed to show that there are various ways and methods to teach a subject to students other than a uniform teaching method. In general, question-answer or narration is professed in the unit of classical logic in the course of logic in particular for the educational circles. And this keeps students in traditional teaching and hebetates them. It is possible to overcome this mentality through activity-based teaching and realize active teaching. In this study, with the introduction of various sample application to the students, $t$ was aimed to show the students that they could also carry out such kind of applications and obtain an engaged learning. In the process of teaching and learning, students are normally desired to involve actively and learn the subject more easily. For that reason, it is believed that students could make such kind of activities by forcing the mental performances of their own students. This study is an exemplary study for such kind of studies likely to be carried out in the future. What is obtained in the study is that a learning outcome could be attained by means of more than one method, technique, application and activity.

\section{References}

2009 Logic Course Curriculum, Ministry of National Education, Ankara.

Aktepe, V. (2010). Effectiveness-based teaching of "benevolence" value in primary school 4th grade social studies lesson and its effect on students' attitudes (Doctoral dissertation). It was obtained from the Higher Education 
Council National Thesis Center. (Thesis No. 279645)

Calp, M. (2006). Teaching from plan to practice (7th ed.). Ankara: Memory.

Calp, M. (2010). Teaching Turkish as a special education area. Ankara: Nobel.

Çapak, İ. (2015). Logic with its outlines (3rd ed.). Istanbul: Ensar.

Çüçen, A. K. (2013). Logic (8th ed.). Bursa: Synthesis.

Demirel, Ö. (2009). Program development in education. Ankara: Pegem.

Duman, E. Z., Arslan, A., \& Küçükşabanoğlu Ö. (2018). Metaphors of University Students Regarding the Concept of "Logic". Abant Izzet Baysal University Faculty of Education Journal, 18(3), 1456-1473. https://doi.org/10.17240/aibuefd.2018.18.39790-421382

Emiroğlu, İ. (2004). Introduction to Classical Logic (2nd ed.). Ankara: Elis.

Gruba, E. G. (1981). Criteria for assessing the trustworthiness of naturalistic inquiries. Educational Technology research and development, 29(2), 75-91. https://doi.org/10.1007/BF02766777

Hee, S. (2005). Activity Based Teaching for Effective Learning. Evani Venkata Anantha Lakshmi Lecturer, $307-389$.

Koç, H., Aksoy, B., Sonmez, Ö.F., \& Yeşiltaş, E. (2010). Teaching Activities Based On Activities And Activities Based Geography Teaching. Journal of Social Sciences Research, 2, 181-19.

Küçükahmet, L. (2007). Planning and evaluation in teaching (13th ed.). Ankara: Nobel.

Oliva, P. F. (1988). Developing the Curriculum. New York: Scott, Foresmand \& Company.

Oner, N. (2014). Classic logic (13th ed.). Ankara: Divan.

Ornstein A. C., \& Hunkins F. P. (1988). Curriculum: Foundations, Principles and Issues. New Jersey: Prentice Hall.

Özçelik, D. A. (2009). Education programs and teaching. Ankara: Pegem.

Özden, Y. (2009). Learning and Teaching (9th ed.). Ankara: Pegem.

Özen, A., \& Ergenekon, Y. (2011). Activity-Based Intervention Practices in Special Education. Educational Sciences: Theory and Practice, 11(1), 359-362.

Özlem, D. (2004). Logic classical / symbolic logic, philosophy of logic (7th ed.). Ankara: Revolution.

Pretti-Frontczak, K. L., Barr, D. M., Macy, M., \& Carter, A. (2003). Researchand Resources related to activitybased intervention, embedded learning opportunities, androutines- based instruction: An annotated bibliography. Topics in Early Childhood Special Education, 23(1), 29-39. https://doi.org/10.1177/027112140302300104

Pretti-Frontczak, K., \& Bricker, D. (2004). An activity-based approach to early intervention. Brookes Publishing Company. PO Box 10624, Baltimore, MD 21285.

Senemoğlu, N. (2004). Development learning and teaching, from theory to practice (9th ed.). Ankara: Gazi.

Shenton, A. K. (2004). Strategies for ensuring trustworthiness in qualitative research projects. Education for information, 22(2), 63-75. https://doi.org/10.3233/EFI-2004-22201

Sonmez, V. (2001). Teacher handbook in curriculum development. Ankara: Memory.

Ural, Ş. (2011). Basic logic (3rd ed.). Istanbul: Cantay.

Yıldırım, C. (1976). Logic Handbook in 100 Questions (1st ed.). Istanbul: Real.

\section{Copyrights}

Copyright for this article is retained by the author(s), with first publication rights granted to the journal.

This is an open-access article distributed under the terms and conditions of the Creative Commons Attribution license (http://creativecommons.org/licenses/by/4.0/). 